\title{
Perbandingan Ekstraksi Ciri Full, Blocks, dan Row Mean Spectrogram Image Dalam Mengidentifikasi Pembicara
}

\author{
La Ode Hasnuddin S Sagala ${ }^{* 1}$, Agus Harjoko ${ }^{2}$ \\ ${ }^{1}$ Program Studi Ilmu Komputer, FMIPA UGM, Yogyakarta \\ ${ }^{2}$ Jurusan Ilmu Komputer dan Elektronika, FMIPA UGM, Yogyakarta \\ e-mail: ${ }^{* 1}$ hasnuddinsagala@yahoo.com, ${ }^{2}$ aharjoko@ugm.ac.id
}

\begin{abstract}
Abstrak
Pada sebuah sistem recognition, pemilihan metode ekstraksi ciri dan ukuran fitur yang digunakan mempengaruhi tingkat keakuratan identifikasi. Berkaitan dengan hal itu, dalam penelitian ini akan dijabarkan perbandingan tiga metode ekstraksi ciri CBIR yaitu row mean image, full image, dan blocks image. Ketiga metode tersebut digunakan untuk mengidentifikasi pembicara dengan menitikberatkan pada ukuran selection feature vector yang digunakan.

Data suara diperoleh dari rekaman suara menggunakan handphone. Rekaman suara berasal dari 10 orang narasumber dengan rincian 5 pria dan 5 wanita. Setiap narasumber mengucapkan lima buah kalimat yaitu Selamat Pagi, Selamat Siang, Selamat Sore, Selamat Malam, dan Dengan Siapa serta diulangi delapan kali tiap kalimat.

Karena menerapkan metode CBIR maka rekaman suara yang berbentuk sinyal dikonversi menjadi image spectrogram menggunakan STFT. Kemudian spectrogram diimplementasikan ke kekre transform lalu diekstrasi cirinya. Penggunaan kekre transform bertujuan untuk menyeleksi dan mengambil kemungkinan-kemungkinan fitur yang optimal serta juga meringankan proses komputasi.

Menggunakan data reference 250 image spectrogram dan data testing 150 image spectrogram memberikan hasil bahwa metode ekstraksi ciri full image memperoleh persentase identifikasi lebih tinggi yaitu 93,3\% dengan ukuran fitur $32 \times 32$.
\end{abstract}

Kata kunci-Identifikasi pembicara, Spektrogram, Transformasi kekre, Full image, Blocks Image, Row mean image

\section{Abstract}

On a system of recognition, selection feature extraction method and feature size are used in identification affects identication rate. In that regard, this study will presents comparison three feature extraction methods namely row mean image, full image, and blocks image. The third method used to identify the speaker with a focus on the size selection feature vector are used.

Sound data obtained from the mobile phone voice recording. Sound recording derived from 10 speakers consisting of 5 men and 5 women. Every speakers pronounce five sentences are Selamat Pagi, Selamat Siang, Selamat Sore, Selamat Malam, and Dengan siapa as well as repeated eight times.

Because applying CBIR methods then the sound recording signal is converted into an image spectrogram using STFT. Spectrogram is formed implemented in kekre transform to extract feature. Using kekre transform aims to select and take the possibilities optimal feature also relieves the computing process.

Using reference data 250 spectrogram and testing data 150 spectrogram produces results that the full image feature extraction methods obtain a higher percentage identification rate is $93,3 \%$ with a feature size of $32 \times 32$.

Keywords - Speaker identification, Spectrogram, Kekre Transform, Full Image, Blocks Image, Row Mean Image

Received Oct 25 ${ }^{\text {th }}$ 2013; Revised April 17 ${ }^{\text {th }}$, 2014; Accepted July 10 $0^{\text {th }}, 2014$ 


\section{PENDAHULUAN}

$\mathrm{P}$ ada sistem identifikasi pembicara atau speaker identification, proses ekstraksi ciri memainkan peranan penting dalam menghasilkan tingkat keakuratan yang baik. Terdapat banyak metode ekstraksi ciri untuk identifikasi pembicara telah diperkenalkan oleh para peneliti. Salah satunya adalah metode ekstraksi ciri berbasis content atau biasa dikenal CBIR (Content Based Image Retrieval).

CBIR (Content Based Image Retrieval) merupakan metode ekstraksi ciri yang menggunakan content yang terdapat pada image sebagai fitur. Content yang digunakan dapat berupa warna, tekstur, shape, atau informasi-informasi lain yang mendukung namun content yang sering digunakan oleh para peneliti adalah warna, tekstur, dan shape.

Penerapan tehnik CBIR ke permasalahan identifikasi pembicara terlebih dahulu dilakukan proses konversi sinyal suara menjadi image dengan menggunakan short time fourier transform atau STFT. Gambar yang dihasilkan oleh STFT berupa spectrogram yang merupakan penampakan spektrum-spektrum frekuensi yang diplot terhadap waktu dan amplitudo. Spectrogram yang digunakan dalam identifikasi pembicara memiliki keuntungan dapat menganalisa suara seseorang sekalipun orang tersebut mencoba untuk menghilangkan karakter asli dari suaranya [1].

Penggunaan content warna sangat memungkinkan jika diterapkan pada spectrogram. Namun penggunaannya terkadang mempengaruhi proses komputasi dan ukuran fitur apalagi jika gambarnya dalam bentuk RGB maka diperlukannya proses setiap plane. Pendekatan CBIR ke dalam transform domain dapat menjadi sebuah solusi pengganti content berdasarkan warna [2]. Penggunaan metode transform bermakna adanya proses transformasi sebelum proses ekstraksi ciri dilakukan.

Salah satu contoh penelitian mengenai ekstraksi ciri CBIR pendekatan transform domain adalah yang dilakukan oleh [3] mengenai identifikasi pembicara. DCT dan Walsh Hadamard transform digunakan sebagai metode transformasi yang akan diimplementasikan ke dalam gambar sebelum diekstraksi cirinya. Setelah proses transformasi, row mean image akan menjadi metode untuk mengambil fitur-fitur yang terdapat pada image. Penggunaan ukuran fitur 64 sampai dengan 8192 akan menjadi perbandingan dalam proses ekstraksi cirinya. Hasilnya menunjukkan bahwa ukuran fitur yang kecil yaitu berukuran 512 menunjukkan pengenalan yang lebih baik.

Persentase pengenalan yang baik pada ukuran fitur yang kecil juga di buktikan pada penelitian [4] mengenai pengenalan wajah. Penelitiannya juga menggunakan DCT dan Walsh sebagai metode transformnya namun metode ekstraksi ciri yang digunakan adalah full image. Hasilnya menunjukkan bahwa dengan menggunakan variasi ukuran fitur $4 \mathrm{x} 4$ sampai dengan $128 \times 128$, ukuran fitur $8 \times 8$ memberikan pengenalan yang baik dibandingkan ukuran fitur yang lain.

Selain penggunaan row mean image dan full image yang dapat memberikan persentase pengenalan yang besar pada ukuran fitur yang kecil, blocks image juga dapat memberikan pengenalan yang baik pada ukuran fitur yang kecil seperti pada penelitian [5] mengenai identifikasi pembicara, akan tetapi cuma menggunakan satu metode transform yakni DCT.

Adanya perbandingan metode ekstraksi ciri yang digunakan namun tetap memberikan hasil pengenalan yang baik pada ukuran fitur yang kecil telah mendorong untuk mengkaji lebih dalam dari ketiga metode ekstraksi ciri tersebut. Oleh karena itulah, melalui penelitian ini akan ditinjau bagaimana perbandingan ketiga ekstraksi ciri yaitu full image, row mean image, dan blocks image dalam mengidentifikasi pembicara dengan meninjau pada ukuran selection feature vector akan tetapi menggunakan kekre transform sebagai metode transformasinya serta manhattan distance sebagai metode feature matching-nya [6]. 


\section{METODE PENELITIAN}

Penelitian ini akan lebih memfokuskan pada proses ekstraksi fitur. Proses ekstraksi fitur yang digunakan adalah full image, row mean image, dan blocks image serta menggunakan metode transform kekre. Ketiga metode tersebut akan dibandingkan untuk mencari metode ekstraksi ciri yang mana yang menghasilkan peforma lebih baik dalam mengidentifikasi pembicara dengan menggunakan manhattan distance sebagai feature matching-nya.

Proses yang dilakukan dalam penelitian ini digambarkan dalam bentuk gambar alir seperti tampak pada Gambar 1. Merujuk pada Gambar 1 memperlihatkan sistem terbagi dalam dua kelompok yakni kelompok reference speech signal dan kelompok test speech signal. Kelompok reference speech signal berfungsi sebagai data-data yang sebelumnya telah dikenali dan disimpan dalam database sedangkan kelompok test speech signal berfungsi sebagai datasample yang akan diujicobakan. Sekilas proses-proses yang terdapat pada dua kelompok tersebut sama namun perbedaanya hanya terdapat pada proses akhir.

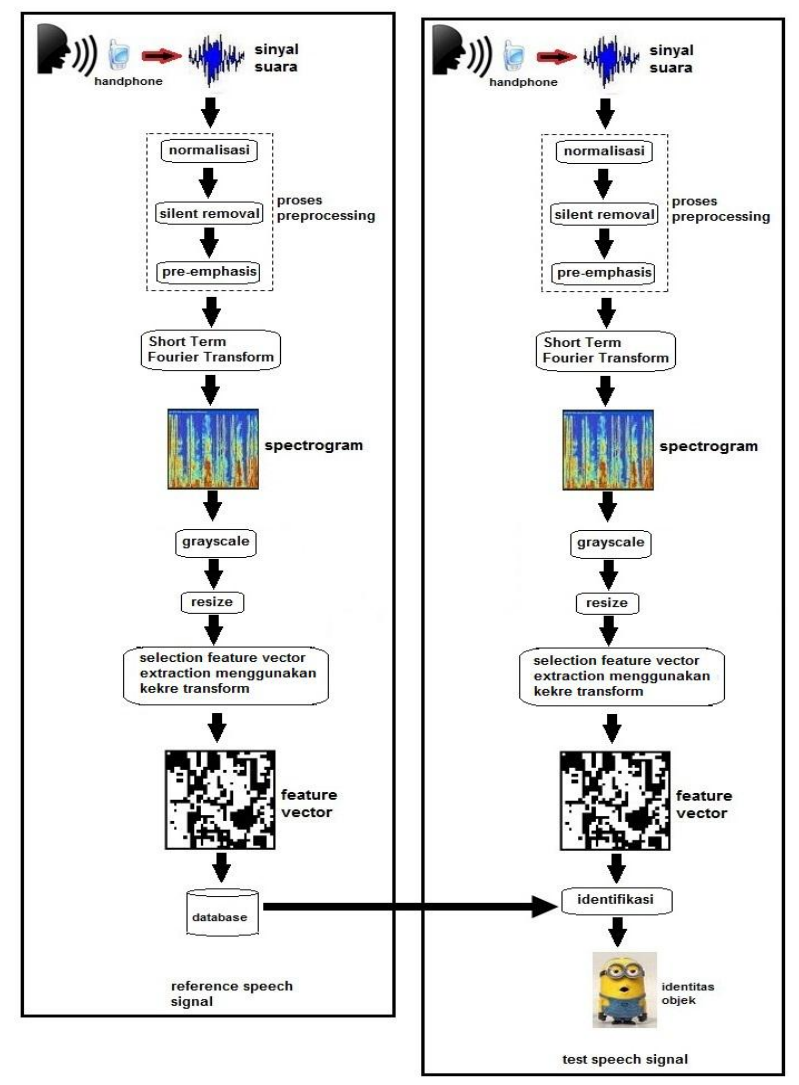

\subsection{Sinyal Suara}

Gambar 1 Sistem Identifikasi Pembicara

Tahap pertama dalam sistem ini adalah pengambilan data rekaman suara menggunakan handphone Nexian bertipe NX-G381i dengan sampling frequency $8000 \mathrm{~Hz}$ dan resolution 16bps. Suara yang diambil berasal dari 10 pembicara dengan rincian 5 pembicara wanita dan 5 pembicara pria. Proses perekamannya dimulai dengan mengucapkan 5 buah kalimat oleh setiap pembicara dan setiap kalimat diulangi sebanyak 8 kali serta disimpan dalam bentuk file WAV. Kalimat tersebut adalah Selamat Pagi, Selamat Siang, Selamat Sore, Selamat Malam dan Dengan Siapa. Rekaman suara yang terbentuk akan dibagi menjadi dua bagian yaitu 5 rekaman sebagai reference signal dan 3 rekaman sebagai test signal untuk setiap kalimat.

\subsection{Proses preprocessing}

Proses ini bertujuan untuk memperbaiki rekaman suara agar menghasilkan sinyal rekaman suara yang baik dan pengaruh-pengaruh noise pada rekaman dapat dikurangi. Pada 
penelitian ini prosesnya terdiri dari tiga bagian yaitu normalisasi, silent removal, dan preemphasis.

\subsubsection{Normalisasi}

Perbedaan intensitas suara dan jarak media rekaman saat proses perekaman terkadang mempengaruhi nilai amplitudo yang dihasilkan. Oleh karena itu untuk mencegah hal tersebut proses normalisasi dilakukan dengan menggunakan persamaan (1).

$$
x_{n}[n]=\frac{x[n]}{\max |x[n]|}
$$

dimana, $\mathrm{n}=1,2,3, \ldots, \mathrm{N}$, $\mathrm{x}$ adalah sinyal suar dan $\max |\mathrm{x}[\mathrm{n}]|$ adalah amplitudo maksimum

\subsubsection{Silent removal}

Pada proses ini, silent removal menggunakan pustaka yang dibuat oleh [7]. Penentuannya dengan menggunakan signal energy dan spectral centroid. Tujuan silent removal untuk menghapus bagian silent dari suara agar proses komputasinya tidak menggunakan waktu yang lama.

\subsubsection{Pre-emphasis}

Proses ini bertujuan untuk memperbaiki sinyal suara dari gangguan noise tetapi tetap mempertahankan frekuensi-frekuensi tinggi yang merupakan data suara. Persamaan (2) menunjukkan rumus yang digunakan.

$$
y[n]=s[n]-\alpha s[n-1] \quad, 0,9 \leq \alpha \leq 1
$$

dimana $y[n]$ merupakan sinyal suara setelah proses preemphasis dan $s[n]$ merupakan sinyal suara sebelum proses preemphasis. Nilai $\alpha$ yang digunakan adalah 0.97

\subsection{Short Term Fourier Transform (STFT)}

Proses STFT merupakan proses yang digunakan untuk mengubah sinyal suara menjadi bentuk image spectrogram. Secara sederhana proses STFT terdiri atas proses frame blocking, windowing, dan fast fourier transform [8].

\subsubsection{Frame blocking}

Proses frame blocking bertujuan untuk membagi sinyal suara menjadi potonganpotongan kecil yang akan mempermudah proses perhitungan dan analisis suara. Gambar 2 menunjukan potongan frame yang diproses.

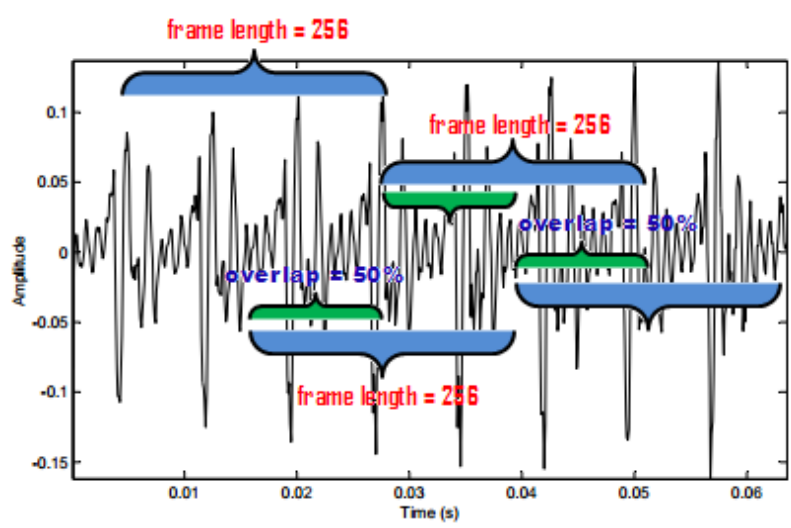

Gambar 2 Proses frame blocking 


\subsubsection{Hamming window}

Proses frame blocking menyebabkan sinyal suara bersifat discontinuelnon-stationary yang dapat menimbulkan frekuensi-frekuensi baru saat dilakukan proses fast fourier transform atau FFT. Oleh karena itu, untuk mencegah hal tersebut perlu adanya proses mengubah sinyal suara dari bersifat discontinue menjadi continue. Salah satu caranya adalah dengan menggunakan proses hamming window. Persamaan (3) menunjukkan rumus hamming window yang digunakan.

$$
W[n]=0.52-0.46 \cos \left(\frac{2 \pi n}{N-1}\right)
$$

dimana, $\mathrm{W}[\mathrm{n}]$ merupakan hasil windowing

\subsubsection{Fast Fourier Transform (FFT)}

Fast fourier transform merupakan metode transform yang digunakan untuk mengubah sinyal suara dalam domain waktu menjadi sinyal suara dalam domain frekuensi. Hasil dari transform ini berupa spektrum-spektrum frekuensi suara.

Rumus FFT seperti ditunjukkan pada persamaan (4) dan untuk mencari nlai spektrum frekuensinya menggunakan persamaan (5)

$$
\begin{aligned}
& X[k]=\frac{1}{N} \sum_{n=1}^{N} x(n)\left(\cos \left(\frac{2 \pi k n}{N}\right)-j \sin \left(\frac{2 \pi k n}{N}\right)\right. \\
& |F(k)|=\left|R^{2}+I^{2}\right|^{1 / 2}
\end{aligned}
$$

dimana, $X[k]$ merupakan hasil proses FFT, $x(n)$ merupakan sinyal suara, $F(k)$ merupakan spektrum frekuensi, $R$ merupakan bilangan real hasil perhitungan dan $I$ merupakan bilangan imajiner hasil perhitungan. Secara kesluruhan, Gambar 3 menunjukkan proses pembentukan spectrogram.

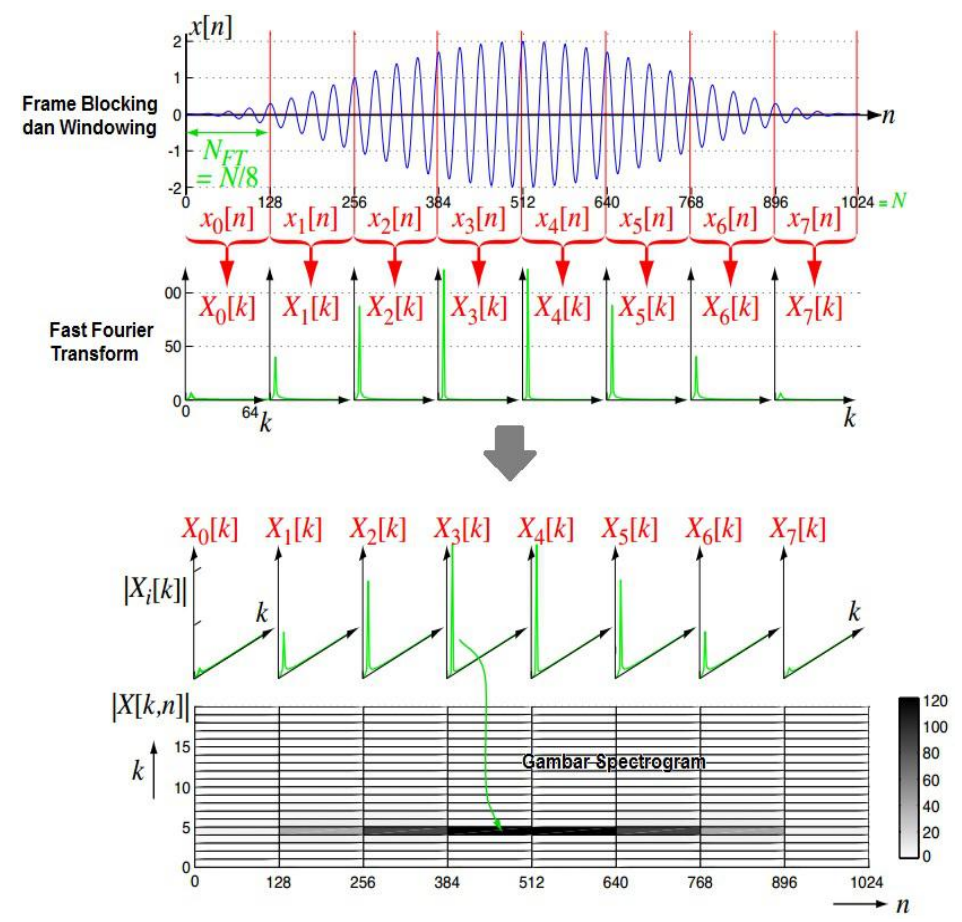

Gambar 3 Pembentukan Spectrogram 


\section{$2.4 \quad$ Grayscale dan Resize}

Proses grayscale merupakan proses konversi gambar dari RGB menjadi grayscale dengan tujuan untuk mempermudah komputasi dan proses resize bertujuan untuk menormalisasikan ukuran tiap spectrogram yang terbentuk. Ukuran normalisasi yang digunakan adalah $256 x 256$.

\subsection{Selection Feature Vector Extraction Menggunakan Kekre}

Proses ekstraksi ciri dalam penelitian ini mengikutsertakan kekre transform sebagai metode untuk menyaring kemungkinan-kemungkinan fitur yang memberikan property yang baik [9]. Penentuan feature vectornya menggunakan tiga metode yaitu full image, row mean image, dan blocks image yang diimplementasikan menggunakan kekre transform seperti pada persamaan (6).

$$
[A]=[K][I][K]^{T}
$$

dimana $[A]$ merupakan hasil transformasi, $[K]$ merupakan matriks kekre, $[I]$ merupakan gambar, dan $[K]^{T}$ adalah matriks kekre transpose.

\subsubsection{Full image}

Ekstraksi ciri yang pertama dilakukan adalah ekstraksi ciri full image. Variasi ukuran ciri yang digunakan adalah 256x256, 128x128, 64x64, 32x32, dan 16x16. Ukuran ciri 256x256 tidak akan mengalami proses dekomposisi sedangkan ukuran selain 256x256 akan mengalami proses dekomposisi. Proses ekstraksi ciri full image seperti ditunjukkan pada Gambar 4.

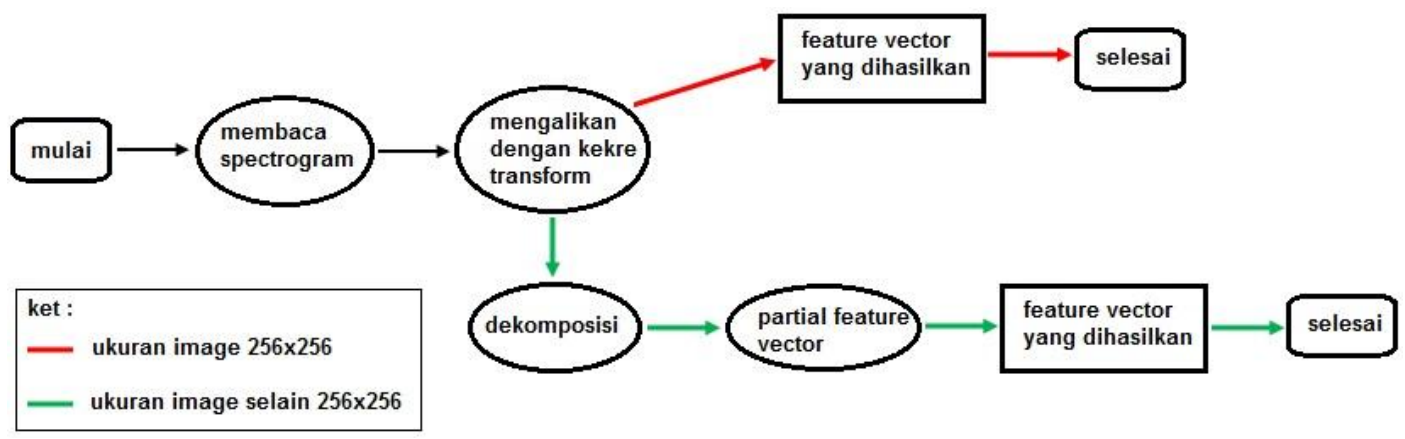

Gambar 4 Bagan alir proses ekstraksi ciri full image

\subsubsection{Row mean image}

Ekstraksi ciri yang kedua dilakukan adalah ekstraksi ciri row mean image. Ekstraksi ciri ini diperoleh dengan cara mengambil nilai mean (rata-rata) piksel tiap baris dan hasilnya disimpan sebagai ciri. Variasi ukuran yang digunakan adalah sama dengan variasi ukuran yang digunakan pada full image. Proses ekstraksi ciri row mean image seperti ditunjukkan pada Gambar 5.

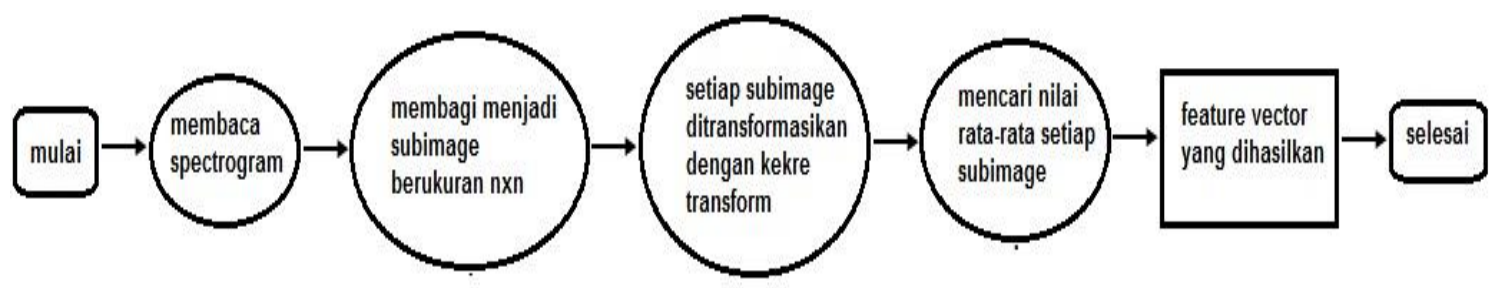

Gambar 5 Bagan alir ekstraksi ciri row mean image

IJCCS Vol. 8, No. 2, July 2014 : 155 - 164 


\subsubsection{Blocks Image}

Ekstraksi ciri yang ketiga atau terakhir digunakan adalah ekstraksi ciri blocks image. Variasi ukuran yang digunakan sama dengan variasi ukuran yang digunakan full image dan row mean image. Seperti full image, ekstraksi ciri blocks image mengalami dua perlakukan yang berbeda yaitu untuk ukuran 256x256 prosesnya dimulai dengan membagi image spectrogram menjadi empat bagian subimage kemudian setiap subimage diimplementasikan ke dalam kekre transform lalu diambil feature vector-nya. Namun untuk ukuran selain 256x256 perlakuannya adalah sebagai berikut :

1. Membagi image spectrogram menjadi subimage dengan ukuran $256 / \mathrm{n} \times 256 / \mathrm{n}$, dimana $\mathrm{n}$ merupakan variasi ukuran yang telah ditetapkan.

2. Mencari nilai rata-rata dari setiap subimage yang bertujuan sebagai perwakilan nilai piksel setiap subimage.

3. Menggabungkan tiap subimage agar membentuk image baru.

4. Image baru tersebut kemudian di block menjadi 4 bagian subimage.

5. Setiap subimage diimplementasikan ke dalam kekre transform

6. Hasil perkaliannya akan berupa feature vector yang disimpan sebagai ciri.

\subsection{Identifikasi}

Proses terakhir dalam penelitian ini adalah proses identifikasi. Metode manhattan distance menjadi eksekutor untuk mengidentifikasi pembicara dengan cara mencari jarak terkecil antara sampel dengan semua data yang terdapat pada database. Jika ditemukan jarak terkecil maka data tersebut akan menjadi kesimpulan dalam proses identifikasi ini. Persamaan (7) merupakan rumus manhattan distance yang digunakan.

$$
d_{i j}=\sum_{k=1}^{n} \mid x_{i k}-x_{j k \mid}
$$

dimana,$x_{i k}$ merupakan data reference, $x_{j k}$ merupakan data testing, dan $d_{i j}$ merupakan nilai jarak.

\subsection{Accuracy of Identification}

Setelah proses identifikasi setiap proses ekstraksi ciri, maka dilanjutkan dengan penentuan persentase besarnya jumlah pembicara yang dikenali. Tujuannya adalah untuk mengetahui ekstraksi ciri yang mana yang memberikan persentase identifikasi yang besar dan pada ukuran fitur berapa. Persamaan (8) menunjukkan rumus yang digunakan.

$$
\text { Accuracy }(\%)=\frac{\text { number of matches }}{\text { number of samples tested }} \times 100 \%
$$

\section{HASIL DAN PEMBAHASAN}

Pada penelitian ini, tiga metode ekstrasi ciri CBIR dengan pendekatan transform dibandingkan keakuratannya dalam mengidentifikasi pembicara dengan meninjau pada ukuran fitur yang digunakan. Berdasarkan pengamatan dengan menggunakan data reference 250 image spectrogram dan data testing 150 image spectrogram menunjukkan bahwa ekstraksi ciri full image memberikan persentase pengenalan lebih besar dibandingkan row mean image dan blocks image.

Pada ekstraksi ciri full image mengenali 140 pembicara atau setara dengan 93,3\%. Ekstraksi ciri blocks image mengenali 139 pembicara atau setara dengan 92,7 \% sedangkan ekstraksi ciri pada row mean image mengenali 132 pembicara atau setara dengan $88 \%$. Tabel 1 menunjukkan hasil pengenalan setiap ekstraksi ciri. 
Tabel 1. Hasil persentase setiap metode ekstraksi ciri

\begin{tabular}{|c|c|c|c|c|}
\hline \multirow{2}{*}{ No } & \multirow{2}{*}{ Ukuran } & \multicolumn{3}{|c|}{ Dikenali (\%) } \\
\cline { 3 - 5 } & & Full image & Blocks image & Row mean image \\
\hline 1 & $16 \times 16$ & 91,3 & 92 & 80,7 \\
\hline 2 & $32 \times 32$ & 93,3 & 92 & 84,7 \\
\hline 3 & $64 \times 64$ & 93,3 & 92,7 & 88 \\
\hline 4 & $128 \times 128$ & 92,7 & 91,3 & 84,7 \\
\hline 5 & $256 \times 256$ & 93,3 & 92 & 61,3 \\
\hline
\end{tabular}

Berdasarkan Tabel 1, ekstraksi ciri full image memberikan pengenalan yang lebih besar pada ukuran fitur 32x32, 64x64, 256x256. Namun karena penelitian ini lebih memfokuskan pada ukuran fitur yang digunakan maka ukuran fitur 32x32 diambil sebagai ukuran fitur yang terbaik dalam penelitian ini dan menobatkan ekstraksi ciri full image sebagai ekstraksi ciri yang memberikan persentase pengenalan lebih besar. Gambar 6 menunjukkan perbedaan persentase akurasi tiap ekstraksi ciri.

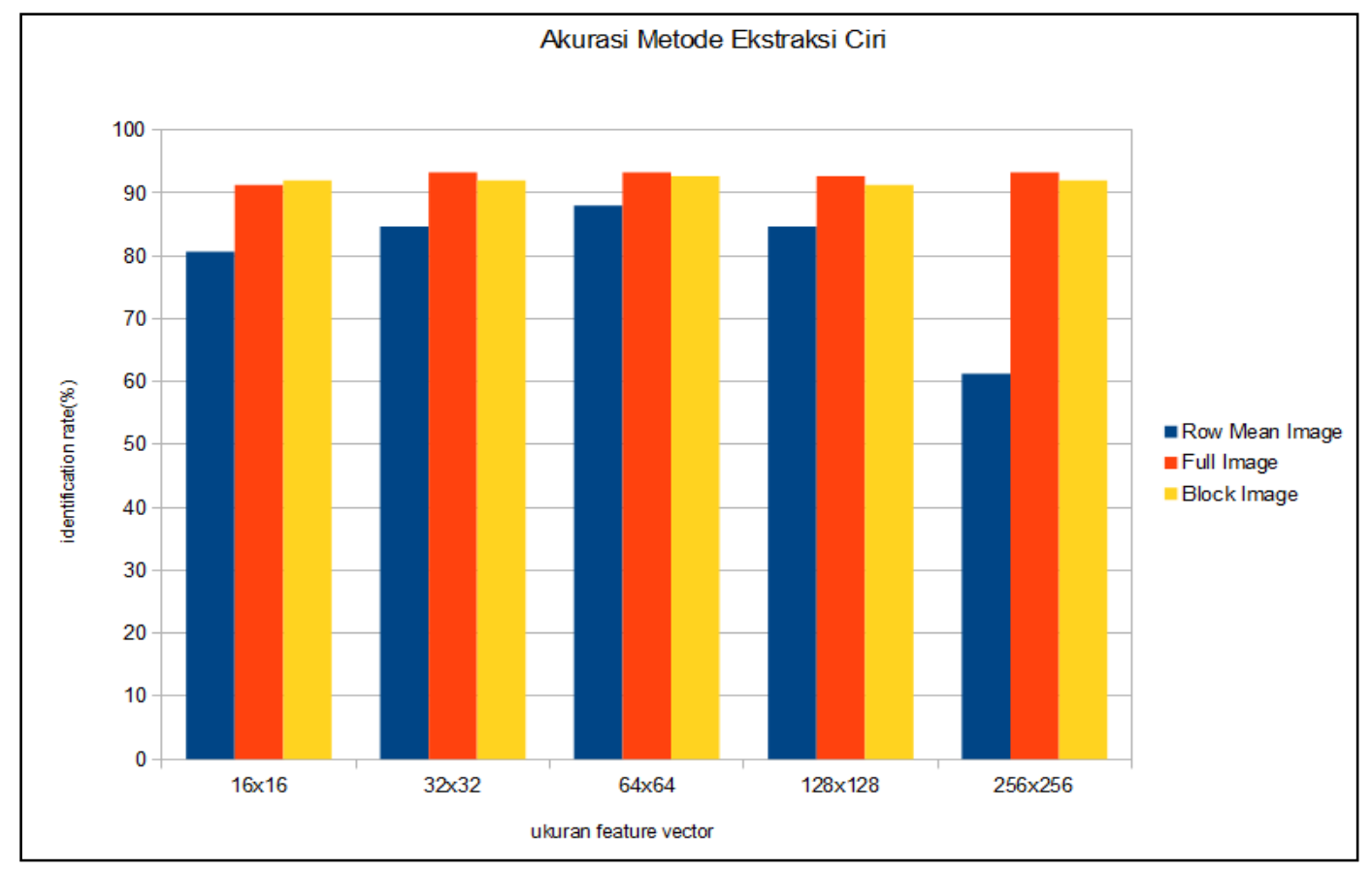

Gambar 6 Diagram batang perbandingan akurasi metode ekstraksi ciri rekaman suara menggunakan handphone

Selain mengambil dari rekaman handphone, pada penelitian ini juga mencoba mengambil rekaman suara yang berasal dari microphone merk X-Tech dengan jenis XH-318. Suara yang direkam disampling dengan frequency $8000 \mathrm{~Hz}$ dan resolution 16bps. Percobaan ini cuma berfungsi sebagai pembanding jika ditinjau dari media rekaman yang digunakan.

Hasil yang diperoleh menunjukkan bahwa ekstraksi ciri blocks image memberikan persentase yang besar dibandingkan dua metode ekstraksi ciri yang lain. Hal ini sangat berbeda jika terjadi pada rekaman suara yang menggunakan handphone, dimana pada rekaman suara tersebut justru yang menunjukkan persentase pengenalan lebih besar adalah ekstraksi ciri full image. Gambar 7 menunjukkan perbedaan persentase tiga metode ekstraksi ciri jika menggunakan microphone sebagai media rekamannya. 


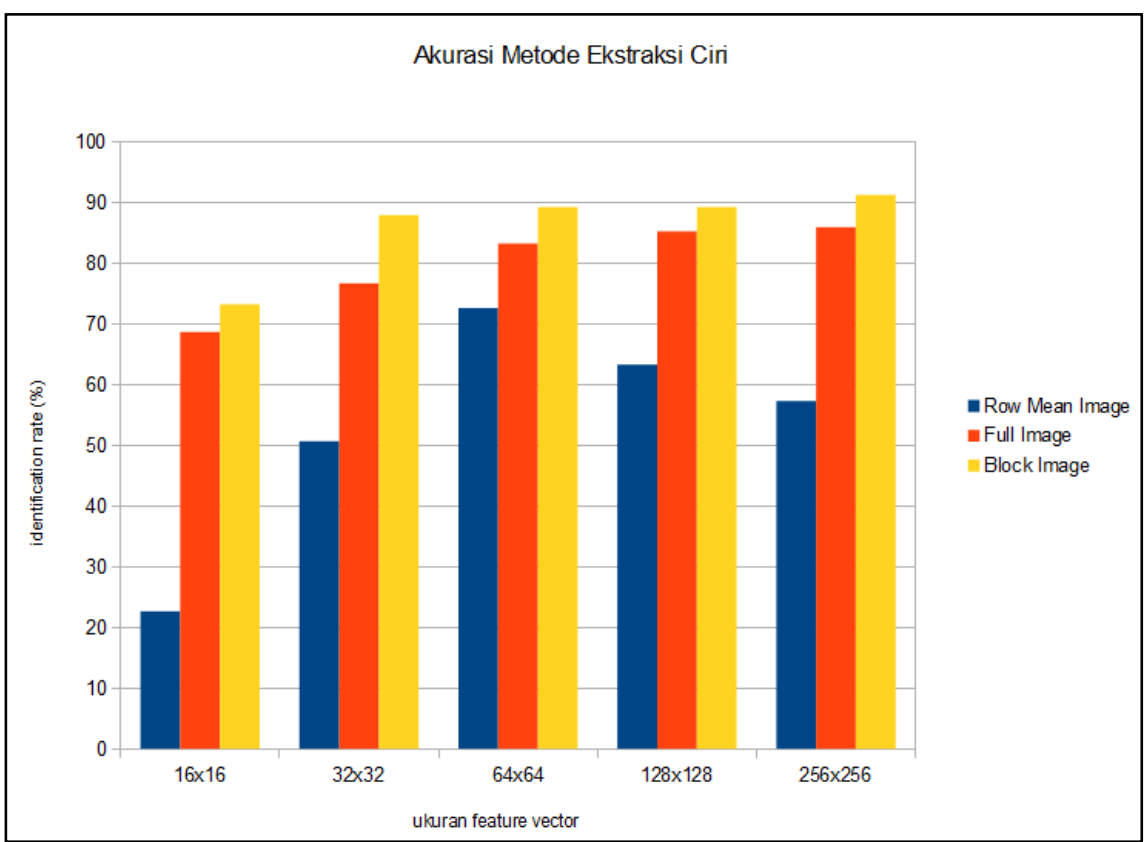

Gambar 7 Diagram batang perbandingan akurasi metode ekstraksi ciri rekaman suara menggunakan microphone

Adanya perbedaan yang dihasilkan baik yang menggunakan microphone ataupun handphone menunjukkan bahwa faktor alat rekaman yang digunakan juga mempengaruhi persentase identifikasi yang dihasilkan. Selain itu juga keragaman lingkungan, keragaman pembicara maupun kondisi perekaman dapat menjadikan tolak ukur mengenai persentase identifikasi yang baik.

\section{KESIMPULAN}

Berdasarkan hasil pengamatan terhadap tiga metode ekstraksi ciri dalam mengidentifikasi pembicara maka dapat disimpulkan sebagai berikut :

- Ekstraksi ciri menggunakan full image memberikan persentase lebih besar dibandingkan row mean image dan blocks image.

- Ukuran fitur yang memberikan persentase pengenalan lebih besar adalah full image pada ukuran $32 \times 32$ sedangkan blocks image dan row mean image masing-masing pada ukuran $64 \times 64$.

\section{SARAN}

Karena sifat kompleksitas yang sering dihadapi pada proses identifikasi pembicara terutama yang berkaitan dengan ukuran fitur ciri yang digunakan maka saran yang bisa dipetik dalam penelitian ini adalah sebagai berikut

- Perlu adanya peninjauan mengenai pengaruh penggunaan kalimat terhadap besarnya persentase keakuratan identifikasi pembicara.

- Peninjauan terhadap penggunaan media rekaman serta pengaruhnya terhadap persentase keakuratan identifikasi. 


\section{DAFTAR PUSTAKA}

[1] Al-Azhar, M.N., 2011, Audio Forensic: Theory and Analysis, Pusat Laboratorium Forensik Polri Bidang Fisika dan Komputer Forensik.

[2] Kekre, H.B. And Thepade, D.S, 2009, Rendering Futuristic Image Retrieval System, National Conference on Enhancements in Computer Communication and Information Technology.

[3] Kulkarni, V. and Kekre, H.B., 2011a, Speaker Identifcation Usiang Row Mean of DCT and Walsh Hadamard Transform, Int. J. on Computer Science and Engineering, Vol 03(03), pp.1295-1301.

[4] Sarode, T., Kekre, H.B., Natu, S. and Natu, P., 2011, Performance Comparison Of Face Recognition Using DCT and Walsh Transform with Full and Partial Feature Vector against KFCG VQ Algorithm, Int. Conference and workshop on Emerging Trends in Technology, pp. 22-30.

[5] Sarode, T., Kekre, H.B., Natu, S. and Natu, P., 2010, Performance Comparison Of 2-D On Full/Block spectrogram And 1-D DCT On Row Mean Of Spectrogram For Speaker Identification, Int. Journal of Biometrics and Bioinformatics, Vol 04(03), pp. 100-112.

[6] Kulkarni, V., Kekre, H.B., Gaikar, P. and Gupta, N., 2012, Speaker Identification using Spectrogram of Varying Frame Sizes, Int. J. of Computer Applications, Vol 50(20), pp. 2733.

[7] Giannakopoulos, 2010, T., A Method for Silence Removal and Segmentation of Speech Signals Implemented in Matlab, Department of Informatics and Telecommunications, University of Athens, Greece.

[8] Ifeachor, Emmanuel, C. And Barrie, W.J., 2002, Digital Signal Processing, Prentice Hall, USA.

[9] Kekre, H.B. And Shah, K., 2009d, Performance Comparison of Kekre's Transform with PCA and Other Conventional Orthogonal Transforms for Face Recognition, Second Int. Conf. On Emerging Trends in Engineering and Technology, pp. 873-879. 